\title{
Correlation between hematological and serological parameters in dengue patients- an analysis of 2022 cases
}

\author{
Rai A. ${ }^{1}$, Azad S. ${ }^{2 *}$, Nautiyal $5 .{ }^{3}$, Acharya $5 .{ }^{4}$ \\ DOI: https://doi.org/10.17511/jopm.2019.i08.07 \\ 1 Anukampa Rai, MD Pathology, Department of Pathology, Shri Guru Ram Rai Institute of Medical \& Health College Of Nursing, Dehradun, \\ Uttarakhand, India. \\ 2* Sheenam Azad, Professor, Department of Pathology, Shri Guru Ram Rai Institute of Medical \& Health College Of Nursing, Dehradun, \\ Uttarakhand, India. \\ 3 Sulekha Nautiyal, Associate Professor, Department of Micobiology, Shri Guru Ram Rai Institute of Medical \& Health College Of Nursing, \\ Dehradun, Uttarakhand, India. \\ 4 Seema Acharya, Professor and Head, Department of Pathology, Shri Guru Ram Rai Institute of Medical \& Health College Of Nursing, \\ Dehradun, Uttarakhand, India.
}

Background: Dengue is a mosquito borne viral disease in the world that has emerged as a major public health problem with its diverse clinical manifestations. Assessment of both the serological and hematological parameters are of importance for the diagnostic and prognostic utility. Aims: To study the various serological and hematological parameters in dengue patients and correlation between them. Materials and Methods: This was a prospective studyof 2022 seropositive dengue cases conducted in a Tertiary care hospital at Dehradun over a period of two years (September 2016August 2018). Hematological analysis was done using SYSMEX XN1000 and various parameters (WBC, RBC and Platelet parameters) were evaluated. The subjects were divided into six serogroups (NS1 positive, NS1+IgM positive, IgM positive, IgG +NS1, IgM+IgG and triple positive) and correlation between different hematological and serological parameters was done using SPSS softwareand ANOVA test was used to calculate the p value. Results: A total of 2022 seropositive cases were studied out of which majority (72.3\%) were NS1 positive. Male predominance was noted. Maximum cases were in the 11-20 year age group. The most affected parameters were platelet count (thrombocytopenia in 62.6\%) and plateletcrit (reduced in 65.6\%). Conclusion: Peripheral blood parameters (esp RBC, Hb, Percentage of neutrophil. lymphocyte and eosinophil, platelet count and plateletcrit) along with serological markers are helpful in disease monitoring and predicting the disease course.

Keywords: Dengue, DENV, ELISA

Corresponding Author

Sheenam Azad, Professor, Department of Pathology, Shri Guru Ram Rai Institute of Medical \& Health College Of Nursing, Dehradun, Uttarakhand, India. Email: sheenam2k1@yahoo.co.in
How to Cite this Article

Rai A, Azad S, Nautiyal S, Acharya S. Correlation between hematological and serological parameters in dengue patients- an analysis of 2022 cases. Trop J Pathol Microbiol. 2019;5(8):547-554. Available From

https://pathology.medresearch.in/index.php/jopm/ar ticle/view/303
To Browse

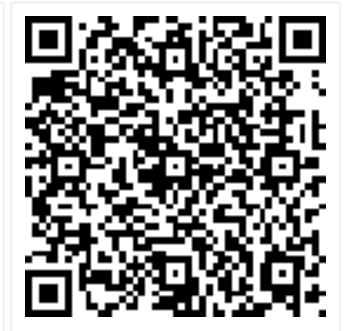

Manuscript Received 2019-06-18

Conflict of Interest No

Review Round 1
2019-06-28
Funding
Nil

Review Round 2
2019-07-04
$\begin{gathered}\text { Ethical Approval } \\ \text { Yes }\end{gathered}$

Review Round 3

Plagiarism X-checker $6 \%$
Accepted 2019-07-08

(c) 2019 by Anukampa Rai, Sheenam Azad, Sulekha Nautiyal, Seema Acharya and Published by Siddharth Health Research and Social Welfare Society. This is an Open Access article licensed under a Creative Commons Attribution 4.0 International License https://creativecommons.org/licenses/by/4.0/ unported [CC BY 4.0]. 


\section{Introduction}

Dengue fever (DF) is an arthropod borne viral diseasecaused by mosquito borne single stranded RNA positive strand Dengue virus (DENV) of the family Flaviviridae, genus Flavivirus $[1,2]$. The disease is transmitted by the female Aedes aegypti and Aedes albopictus mosquito which transmit the virus during the blood meal. In recent years, DF has become a major international health problem affecting tropical and sub-tropical regions around the world - especially urban and peri-urban areas $[3,4]$. The global annual incidence is about 390 million dengue infections per year, of which 96 million manifests clinically [5]. It presents with a diverse clinical picture that ranges from asymptomatic illness to DF to the severe illness of dengue hemo-rrhagic fever (DHF)/ dengue shock syndrome (DSS).

The preliminary diagnosis relies on the clinical symptoms. The confirmation of the diagnosis is routinely done by serological tests. The methods include detection of virus by cell culture and immunofluorescence, detection of virus antigen by Enzyme Linked Immunosorbent Assay (ELISA), detection of anti dengue virus antibody by haemagglutination inhibition ( $\mathrm{HI})$, complement fixation test (CF), neutralization test, ELISA and detection of virus nucleic acid by Real Time Reverse Transcription Polymerase Chain Reaction (RT-PCR) $[6,7]$.

To diagnose the acute infection, the preferred method used these days is detection of Non Structural 1(NS1) protein and IgM and IgG anti dengue virus antibody using in vitro immunochromatographic assay. NS1 is a highly conserved glycoprotein which is present in high concentrations in the serum of dengue-infected patients from Day 1 to Day 9 after the onset of fever $[6,7]$. In case of primary dengue infection, IgM becomes detectable on Day 3 to 5 of illness and persist for 2 to 3 months, whereas IgG appear by the fourteenth day and persist for life. Therefore, patients with secondary infections will have a positive IgG result, usually, but not always with a positive IgM result $[8,9]$. There is alteration in various hematological parameters during dengue fever. Leuopenia, thrombocytopenia and presence of atypical lymphocytes are commonly observed in dengue cases. Raised hematocrit (Hct) is a known finding in dengue hemorrhagic fever $[10,11]$.
The incidence and prevalence of seropositive dengue cases has been on a steady increase over the past decade. Therefore monitoring of these parameters can help reduce the dengue related morbidity and mortality. The present study aimed to evaluate the various serological and hematological parameters in dengue fever and study the correlation between them. Most of the studies conducted till date has been over one seasonal outbreak with lesser number of cases. To the best of the present knowledge, this is the first study comprising larger subset of patients and carried over a period of two years.

\section{Materials and Methods}

Type of study: Prospective study

Duration: Two years (September 2016-August 2018)

Location: Central Lab, Department of Pathology at SGRRIM \& HS and Shri Mahant Indiresh Hospital, Dehradun.

Ethical consideration and permission:The study was approved by research and ethical committee of the institute.

Inclusion criteria: All the seropositive cases of dengue during the study period were included.

Exclusion criteria: Patients with fever but negative for dengue serological markers and patients with only IgG positive serology were excluded from the study.

Sampling method:The serological tests were done using SD BIOLINE Duo Rapid Test Kit. NS1 antigen alone positivity indicates the early phase of illness. The concurrent NS1 antigen and IgM antibody positive status shows early phase of the illness. Triple positives indicate an early phase of a secondary infection. During the acute phase of the disease, the presence of IgM antibody alone indicates a primary infection. Based upon this, cases were divided into 6 serogroups i.e. NS1 positive, NS1+IgM positive, IgM positive, IgG +NS1 positive, IgM+ IgG positive and triple positive.

For hemaotological analysis, EDTA sample was run in SYSMEX XN1000. Peripheral blood examination and complete blood counts were done in all the cases and the following hematological parameters were analysed-Hemoglobin ( $\mathrm{Hb})$, Red blood cell (RBC) count, Hematocrit (Hct), Mean Corpuscular Volume (MCV), Mean Corpuscular hemoglobin 
$(\mathrm{MCH})$, Mean Corpuscular Hemoglobin Concentration (MCHC), Red Cell Distribution Width-Coefficient of Variation (RDW-CV), Total leukocyte count (TLC), Differential leucocyte count (DLC), Platelet Count $(\mathrm{P} / \mathrm{C})$, Platelet Distribution Width (PDW), Mean Platelet Volume (MPV), Platelet-Large Cell Ratio (PLCR) and Plateletcrit (PCT). Mean value of each parameter was calculated using SPSS software. Annova test was used to calculate the $p$ value to find correlation between hematological and serological parameters

\section{Results}

Amongst 2022 cases, majority (83.13\%) were seen in the year 2016 followed by $16.71 \%$ cases in the year 2017. During the year 2016 and 2017 maximum number of cases were seen in the month of September i.e. $56.04 \%$ and $44.37 \%$ respectively. Teenagers and young adults are most commonly affected as $30.8 \%$ cases were in the age group of 11-20 years. Least number of cases were seen in elderly $(1.6 \%)$. There was male predominance (M:F- 1.8:1). The distribution of cases into 6 serogroups is shown in Table 1.

Table-1: Groups of serum markers

\begin{tabular}{|l|l|}
\hline \multicolumn{1}{|c|}{ NS1 Positive } & \multicolumn{1}{|c|}{1461 (72.3\%) } \\
\hline NS1+IgM Positive & $241(11.9 \%)$ \\
\hline IgM Positive & $182(9 \%)$ \\
\hline IgG+NS1 Positive & $74(3.7 \%)$ \\
\hline IgM+ IgG Positive & $41(2 \%)$ \\
\hline NS1 + IgM + IgG Positive & $23(1.1 \%)$ \\
\hline
\end{tabular}

Evaluation of various hematological parameters (RBC Parameters, WBC Parameters, Platelet Parameters) is shown in Table 2.

Table-2: Evaluation $\begin{aligned} & \text { of } \\
& \text { parameters }\end{aligned}$
\begin{tabular}{|l|l|l|l|}
\hline \multicolumn{1}{|c|}{ Parameter } & \multicolumn{1}{c|}{$\begin{array}{c}\text { Decreased N } \\
(\%)\end{array}$} & \multicolumn{1}{|c|}{$\begin{array}{c}\text { Normal N } \\
(\%)\end{array}$} & $\begin{array}{c}\text { Increased N } \\
(\%)\end{array}$ \\
\hline RBC & $398(19.7)$ & $1153(57)$ & $471(23.3)$ \\
\hline Hb & $514(25.4)$ & $1408(69.7)$ & $100(4.9)$ \\
\hline Hct & $530(26.2)$ & $1375(68)$ & $117(5.8)$ \\
\hline RDW-CV & $13(0.7)$ & $1325(65.5)$ & $684(33.8)$ \\
\hline MCV & $555(27.4)$ & $1402(69.4)$ & $65(3.2)$ \\
\hline MCH & $480(23.7)$ & $1346(66.6)$ & $196(9.7)$ \\
\hline MCHC & $202(10)$ & $1603(79.3)$ & $219(10.7)$ \\
\hline TLC & $764(37.8)$ & $1113(55)$ & $145(7.2)$ \\
\hline Neutrophil percentage & $764(37.8)$ & $1113(55)$ & $145(7.2)$ \\
\hline Lymphocyte & $197(9.7)$ & $1427(70.6)$ & $398(19.7)$ \\
percentage & & & \\
\hline
\end{tabular}

\begin{tabular}{|l|l|l|l|}
\hline Monocyte percentage & $100(4.9)$ & $1870(92.5)$ & $52(2.6)$ \\
\hline Eosinophil percentage & $815(40.3)$ & $1160(57.4)$ & $47(2.3)$ \\
\hline PIt Count & $1266(62.6)$ & $744(36.8)$ & $14(0.6)$ \\
\hline PDW & $45(2.3)$ & $1105(54.6)$ & $872(43.1)$ \\
\hline MPV & $38(1.9)$ & $1195(59.1)$ & $789(39)$ \\
\hline P-LCR & $49(2.5)$ & $1298(64.2)$ & $674(33.3)$ \\
\hline PCT & $1326(65.6)$ & $662(32.7)$ & $36(1.7)$ \\
\hline
\end{tabular}

Mean value was calculated for each hematological parameters and most of them had mean values within reference range except platelet count (129.89 $X 103 / \mu \mathrm{l}$ ) and plateletcrit (females- $0.14 \%$ and males- $0.16 \%$ ). The mean value in different serogroups were also obtained. It was observed that there was a significant association of hemoglobin. platelet count, plateletcrit, TLC, percentage of neutrophil. lymphocyte and eosinophil with serological groups ( $p$ value $=<0.05$ in both the sex).

In addition, $\mathrm{RBC}$ count also showed a significant association $(p<0.05)$ in males (Table 3 ). MCV, MCH, MCHC, RDW-SD, RDW-CV, monocyte percentage, hematocrit, PDW, MPV, P-LCR in both the sex and RBC count in females did not have any correlation between different serogroups.

Table-3: ANOVA test (to study the correlation between the serological and hematological groups) 3(A) - RBC Parameters.

\begin{tabular}{|c|c|c|c|c|c|}
\hline RBC Variables & Group & $\mathbf{N}$ & Mean & SD & p-value \\
\hline \multirow[t]{6}{*}{ Hemoglobin (females) } & IgM Positive & 52 & 11.86 & 1.79 & \multirow[t]{6}{*}{$<0.05$} \\
\hline & NS1 Positive & 537 & 12.35 & 1.68 & \\
\hline & IgM + NS1 Positive & 91 & 12.76 & 1.54 & \\
\hline & IgG + IgM Positive & 12 & 12.13 & 3.24 & \\
\hline & IgG + NS1 Positive & 24 & 13.11 & 1.75 & \\
\hline & Triple Positive & 3 & 13.83 & 0.72 & \\
\hline \multirow[t]{6}{*}{ Hemoglobin (males) } & IgM Positive & 130 & 13.98 & 2.24 & \multirow[t]{6}{*}{0.004} \\
\hline & NS1 Positive & 924 & 14.29 & 1.87 & \\
\hline & IgM + NS1 Positive & 150 & 14.76 & 1.94 & \\
\hline & IgG + IgM Positive & 29 & 14.38 & 2.07 & \\
\hline & IgG + NS1 Positive & 50 & 14.95 & 2.01 & \\
\hline & Triple Positive & 20 & 14.57 & 1.50 & \\
\hline \multirow[t]{6}{*}{$\mathrm{RBC}$ (males) } & IgM Positive & 130 & 4.83 & 0.77 & \multirow[t]{6}{*}{0.008} \\
\hline & NS1 Positive & 924 & 4.94 & 0.69 & \\
\hline & IgM + NS1 Positive & 150 & 5.11 & 0.75 & \\
\hline & IgG + IgM Positive & 29 & 4.94 & 0.71 & \\
\hline & IgG + NS1 Positive & 50 & 5.15 & 0.67 & \\
\hline & Triple Positive & 20 & 5.09 & 0.66 & \\
\hline
\end{tabular}

In RBC parameters, hemoglobin (males and females) and RBC (males) shows correlation with serogroups. 
Rai A. et al: Correlation between hematological and serological

Table 3 (B)- WBC parameters

\begin{tabular}{|c|c|c|c|c|c|}
\hline WBC Variables & Group & $\mathbf{N}$ & Mean & SD & p-value \\
\hline \multirow[t]{6}{*}{ Total Leucocyte Count (males and females) } & IgM Positive & 182 & 7340.93 & 4672.28 & \multirow[t]{6}{*}{$<0.01$} \\
\hline & NS1 Positive & 1461 & 5185.36 & 2816.70 & \\
\hline & IgM + NS1 Positive & 241 & 4407.10 & 2564.39 & \\
\hline & IgG + IgM Positive & 41 & 7868.29 & 4184.02 & \\
\hline & IgG + NS1 Positive & 74 & 5858.38 & 3274.16 & \\
\hline & Triple Positive & 23 & 5295.22 & 2720.75 & \\
\hline \multirow[t]{6}{*}{ Neutrophil (\%) (males and females) } & IgM Positive & 182 & 59.69 & 17.24 & \multirow[t]{6}{*}{$<0.01$} \\
\hline & NS1 Positive & 1461 & 68.02 & 16.04 & \\
\hline & IgM + NS1 Positive & 241 & 53.53 & 15.50 & \\
\hline & IgG + IgM Positive & 41 & 58.15 & 19.65 & \\
\hline & IgG + NS1 Positive & 74 & 53.97 & 17.28 & \\
\hline & Triple Positive & 23 & 53.65 & 14.79 & \\
\hline \multirow[t]{6}{*}{ Lymphocyte (\%) (males and females) } & IgM Positive & 182 & 34.17 & 16.06 & \multirow[t]{6}{*}{$<0.01$} \\
\hline & NS1 Positive & 1461 & 25.97 & 15.17 & \\
\hline & IgM + NS1 Positive & 241 & 39.64 & 14.65 & \\
\hline & IgG + IgM Positive & 41 & 35.78 & 18.05 & \\
\hline & IgG + NS1 Positive & 74 & 39.11 & 16.88 & \\
\hline & Triple Positive & 23 & 39.09 & 12.48 & \\
\hline \multirow[t]{6}{*}{ Eosinophil (\%) (males and females) } & IgM Positive & 182 & 1.65 & 2.19 & \multirow[t]{6}{*}{$<0.01$} \\
\hline & NS1 Positive & 1460 & 1.12 & 1.85 & \\
\hline & IgM + NS1 Positive & 241 & 1.98 & 2.60 & \\
\hline & IgG + IgM Positive & 41 & 1.44 & 1.57 & \\
\hline & IgG + NS1 Positive & 73 & 1.75 & 2.30 & \\
\hline & Triple Positive & 23 & 1.48 & 1.56 & \\
\hline
\end{tabular}

In WBC parameters, total leucocyte count, percentage of neutrophil, lymphocyte and eosinophil show correlation with serogroups.

Table 3 (C)- Platelet parameters

\begin{tabular}{|c|c|c|c|c|c|}
\hline Platelet Variables & Group & $\mathbf{N}$ & Mean & SD & P- value \\
\hline \multirow[t]{6}{*}{ Platelet count(males and females) } & IgM Positive & 182 & 146.80 & 107.55 & \multirow[t]{6}{*}{$<0.01$} \\
\hline & NS1 Positive & 1461 & 135.50 & 78.13 & \\
\hline & IgM + NS1 Positive & 241 & 109.76 & 63.80 & \\
\hline & IgG + IgM Positive & 41 & 116.59 & 129.75 & \\
\hline & IgG + NS1 Positive & 74 & 77.68 & 85.94 & \\
\hline & Triple Positive & 23 & 59.91 & 62.02 & \\
\hline \multirow[t]{6}{*}{ PCT(Females) } & IgM Positive & 52 & 0.19 & 0.12 & \multirow[t]{6}{*}{0.004} \\
\hline & NS1 Positive & 537 & 0.17 & 0.09 & \\
\hline & IgM + NS1 Positive & 91 & 0.14 & 0.07 & \\
\hline & IgG + IgM Positive & 12 & 0.16 & 0.13 & \\
\hline & IgG + NS1 Positive & 24 & 0.14 & 0.11 & \\
\hline & Triple Positive & 3 & 0.06 & 0.07 & \\
\hline \multirow[t]{6}{*}{ РCT(Males) } & IgM Positive & 130 & 0.17 & 0.13 & \multirow[t]{6}{*}{$<0.01$} \\
\hline & NS1 Positive & 924 & 0.15 & 0.13 & \\
\hline & IgM + NS1 Positive & 150 & 0.13 & 0.07 & \\
\hline & IgG + IgM Positive & 29 & 0.12 & 0.12 & \\
\hline & IgG + NS1 Positive & 50 & 0.10 & 0.11 & \\
\hline & Triple Positive & 20 & 0.10 & 0.08 & \\
\hline
\end{tabular}

In platelet parameters, platelet count and plateletcrit shows correlation with serogroups. 


\section{Discussion}

Dengue fever is a growing public health concern in most tropical countries. To decrease the dengue related mortality and morbidity, it is very important to know the various hematological parameters that are altered during the illness. It is equally important to know the various serological parameters and their interpretation.

Over the past few years, there has been a decline in the number of dengue cases probably due to the increasing awareness amongst the people with the help of various health programs and campaigns in media as well as change in their health seeking behavior.

The lower infection rates in females of Asian community could also be due to the fact that many of them remain at home and are less exposed to this vector borne infection [12]. Also, the immune response in females is more competent than in males, resulting in greater production of cytokines, thus providing protection [13]. Peripheral blood parameters (Hemogram) revealed a wide range of variation from normal to decrease or increase when compared with the normal reference range.

Hemoglobin values were normal in majority of the cases and mean was $13.30 \mathrm{~g} / \mathrm{dl}$ in females and $13.75 \mathrm{~g} / \mathrm{dl}$ in males. Anaemia was seen in only $25.4 \%$ of the cases. Low $\mathrm{Hb}$ levels can be due to Disseminated Intravascular Coagulation (DIC), where chemicals responsible for clotting are used up and lead to severe bleeding [14].

At the same time, significantly higher level of hemoglobin were seen in the acute phase due to fluid leakage leading to concentration of plasma, causing a rise in hemoglobin [15]. Plasma leakage occurs due to cytokine release which is manifested as haemoconcentration and is seen as increase in hematocrit $20 \%$ above average for age, sex and population. It should be remembered that, with the progression to $\mathrm{DHF}$, there is a $20 \%$ increase in hematocrit from the baseline along with presence of thrombocytopenia [16, 17]. In the present study, raised hematocrit was seen only in $5.8 \%$ of the cases. It was normal in $68 \%$ cases and mean hematocrit values were $40.78 \%$ in females and $41.59 \%$ in males. RDW-CV and RBC indices were normal in majority of the subjects. $\mathrm{MCH}$ and $\mathrm{MCHC}$ had a mean value of $28.66 \mathrm{pg}$ and $33.06 \mathrm{~g} / \mathrm{dl}$ respectively which was in agreement with Advani et al [18].
Out of all the RBC parameters, the mean value of hemoglobin (males and females) and RBC count (males) calculated in different serogroups revealed a significant correlation amongst different serogroups. Leucopenia was noted in $37.8 \%$ of the cases in this study which was in concordance with studies by Rusmavati et al and Dutta et al where leucopenia had been reported in $33.3 \%$ and $30 \%$ respectively[19, 20]. However, few other studies reported leucopenia in larger subset ranging from $49-60 \%[21,22,23]$. Leucopenia occurs due to bone marrow suppression by the virus in acute phase. A small subset of patients $(7.2 \%)$ revealed leucocytosis which may be seen secondary to superadded bacterial infection or in the presence of hemorrhagic shock. Neutropenia is attributed to decrease in granulocytes due to bone marrow suppression in early phase as well as marked degeneration of mature neutrophils during the febrile phase [29]. It was observed in $37.8 \%$ of the cases where as neutrophilia was noted in only $7.2 \%$ of the cases in the present study. Neutrophilia has been attributed mainly to stress induced shift to left [24]. Mean value of neutrophil percentage was $64.66 \%$. Lymphocytosis was observed in only $19.7 \%$ of the cases in the present study. There were no significant atypical lymphocytes and plasmacytoid lymphocytes although few studies have shown both atypical lymphocytes and plasmacytoid lymphocytes in dengue [11, 22, 24]. Mean value of lymphocyte percentage was $29.18 \%$.

Eosinophilia was observed in $40.3 \%$ cases in the present study which is in concordance with a few studies $[22,25]$. Eosinophilia is more common during the convalescence phase and is regarded as the recovery parameter in dengue [22]. Mean value of eosinophil percentage was $1.30 \%$. The phase of illness was not recorded in this study. Hence, the rise during convalescence cannot be commented upon. Monocytes are major targets of Dengue viruses. Monocytosis along with thrombocytopenia is an early and consistent guide in diagnosis of Dengue and a marker of severe Dengue [24]. Monocytosis was noted in only $4.9 \%$ of the cases which was in concordance with study by Joshi et al where monocytosis was observed in $5 \%$ of the cases [24]. The mean value of percentage of neutrophil. lymphocyte and eosinophil calculated in different serogroups revealed a significant correlation amongst these serogroups ( $p$ value $<0.01$ for all three i.e. Neutrophil percentage, Lymphocyte percentage and Eosinophil percentage). 
Platelets are involved in hemostasis, tissue repairing and infection. They are the natural sources of various growth factors like Platelet Derived Growth Factor (PDGF), Vascular Endothelial Growth Factor (VEGF), Insulin Like Growth Factor-1 (IGF-1) and Transforming Growth Factor $\beta$ (TGF- $\beta$ ). These growth factors have an important role in inflammation, angiogenesis, repair and regeneration of tissues [26]. Activation of platelets causes morpho-logical alterations in them. Thrombocytopenia is a common finding in dengue patients $[18,20,22,24]$. It was noted in $62.6 \%$ cases in the present study.The mean value of platelet count was also reduced $(129.89 \times 103 / \mu \mathrm{l})$ in this study. It is attributed to the direct bone marrow suppression by the virus, anti dengue antibodymediated platelet destruction, peripheral consumption of platelets and isolated viral replication in the platelet.

The release of high levels of platelet activating factor may induce platelet consumption and augment adhesiveness of vascular endothelial cells resulting in thrombocytopenia $[27,28]$. A notable decrease in platelet count with disease progression and in secondary dengue infection was observed in the present study emphasizing the need to regularly monitor the platelet count during the illness to avoid bleeding complications. Upon activation, the platelets exhibit morphological changes. There is an increase in the number of pseudopodia and variation in their sizes leading to alterations in the platelet distribution width (PDW) [29]. In the present study, only $43.1 \%$ of the cases had increased PDW and the mean value of PDW was 15.68fL in females and 14.99fL in males. MPV acts as a surrogate marker of bone marrow activity. A high MPV indicates increased megakaryocyte activity where as a low MPV indicates marrow suppression and increased risk of bleeding [30].

In the present study, MPV values were normal in $60 \%$ of the cases with a mean value of $12.10 \mathrm{fL}$ in females and $11.76 \mathrm{fL}$ in males. Platelet large cell ratio is defined as the percentage of platelets that exceed the normal volume of $12 \mathrm{fL}$ in the total platelet count [31].

Approximately $65 \%$ of the cases had normal P-LCR in the present study with a mean value of $40.03 \%$ in females and $38.92 \%$ in males. Plateletcrit, a measure of total platelet mass and an effective screening tool for detecting platelet quantitative abnormalities was reduced in majority of the subjects (65.6\%) and was normal in $32.7 \%$.
Mean value of platecrit was reduced in the study in both the sex $(0.14 \%$ in females and $0.16 \%$ in males). Lower Plateletcrit is due to the reduced biomass index of the platelets in the peripheral blood. Amongst all the platelet parameters, only the platelet count and plateletcrit had significant correlation when compared amongst different serogroups ( $p \leq 0.01$ for platelet count; $p \leq 0.04$ for plateletcrit).

Limitation: This study established statistical significance between hematological and serological parameters in dengue patients however, the clinical significance of the same was not evaluated.

\section{Conclusion}

Platelet count, TLC, Hemoglobin, Plateletcrit, Percentage of neutrophil. lymphocyte and eosinophil if rightly and timely assessed, these can be of value for better care of dengue patients. Future studies to assess the clinical significance and utility of correlation between haematological and serological parameters in prognosticating and managing dengue patients of dengue is recommended.

\section{What this study adds to existing knowledge?}

Certain peripheral blood parameters ( $\mathrm{RBC}, \mathrm{Hb}$, Percentage of neutrophil. lymphocyte and eosinophil, platelet count and plateletcrit) have a correlation with serological groups. Hence, monitoring them may be helpful in disease monitoring and predicting the disease course.

\section{Author's contribution}

Dr. Anukampa Rai: Concept, Study design, Data Collection, Statistical analysis, Literature review, Discussion. Dr. Sheenam Azad: Concept, Study design, Data Collection, Statistical analysis, Literature review, Discussion. Dr. Sulekha Nautiyal: Concept, Study design, Data Collection, Discussion. Dr. Seema Acharya: Concept, Study design, Discussion.

\section{Reference}

01. Halstead SB. Pathogenesis of denguechallenges to molecular biology. Science. 1988;239(4839)476-481. doi: 10.1126/science.3277268 [Crossref][PubMed] [Google Scholar] 
02. Kurane I. Dengue hemorrhagic fever with special emphasis on immunopathogenesis. Comp Immunol Microbiol Infect Dis. 2007 Sep;30(56)329-340. doi: 10.1016/j.cimid.2007.05.010 [Crossref][PubMed][Google Scholar]

03. Gubler DJ. Dengue and dengue hemorrhagic fever. Clin Microbiol Rev. 1998;11(3)480-496. doi: 10.1128/CMR.11.3.480 [Crossref][PubMed][Google Scholar]

04. Guzman MG, Halstead SB, Artsob $H$, Buchy $P$, Farrar J, Gubler DJ, et al. Dengue- a continuing global threat. Nat Rev Microbiol. 2010;8(12 Suppl)S7-S16. doi: 10.1038/nrmicro2460 [Crossref] [PubMed][Google Scholar]

05. Bhatt S, Gething PW, Brady OJ, Messina JP, Farlow AW, Moyes $\mathrm{CL}$, et al. The global distribution and burden of dengue. Nature. 2013;496(7446)504-507. doi: 10.1038/nature12060 [Crossref][PubMed][Google Scholar]

06. Young PR, Hilditch PA, Bletchly C, Halloran W. An antigen capture enzyme-linked immunosorbent assay reveals high levels of the dengue virus protein NS1 in the sera of infected patients. J Clin Microbiol. 2000;38(3)1053-1057. [Crossref][PubMed][Google Scholar]

07. Alcon S, Talarmin A, Debruyne M, Falconar A, Deubel $V$, Flamand $M$. Enzyme-linked immunosorbent assay specific to Dengue virus type 1 nonstructural protein NS1 reveals circulation of the antigen in the blood during the acute phase of disease in patients experiencing primary or secondary infections. J Clin Microbiol. 2002;40(2)376-81. doi: 10.1128/jcm.40.02.376381.2002 [Crossref][PubMed][Google Scholar]

08. Shu PY, Huang JH. Current advances in dengue diagnosis. Clin Diagn Lab Immunol. 2004;11(4)642650. doi: 10.1128/CDLI.11.4.642-650.2004 [Crossref][PubMed][Google Scholar]

09. Gubler DJ. Serological diagnosis of dengue haemorrhagic fever. Dengue Bull. 1996;20;20-23. [Crossref][PubMed][Google Scholar]

10. Azin FR, Gonçalves RP, Pitombeira MH, Lima DM, Castelo Branco I. Dengue- profile of hematological and biochemical dynamics. Rev Bras Hematol Hemoter. 2012;34(1)36-41. doi: 10.5581/15168484.20120012 [Crossref][PubMed][Google Scholar]
11. Mehta RC, Goswami HM, Katara RK, Patel PS, Parikh UV, Vegad MM, Jain PY. Importance of complete blood count and peripheral smear examination in early diagnosis of dengue patients. J Infect Dis Let. 2013;2(1)22-24. [Crossref][PubMed] [Google Scholar]

12. Kidwai AA, Jamal Q, Farooqi FR, Ullah $\mathrm{S}$. Serodiagnosis of dengue infection using rapid immunochromatography test in patients with probable dengue infection. J Pak Med Assoc. 2010; 60(11)936-9. [Crossref][PubMed][Google Scholar]

13. Halstead SB, Nimmannitya $S$, Cohen SN. Observations related to pathogenesis of dengue hemorrhagic fever- IV, Relation of disease severity to antibody response and virus recovered. Yale J Biol Med. 1970;42(5)311-328. [Crossref][PubMed] [Google Scholar]

14. Kaur R, Babita, Sama P. Hematological and biochemical changes in dengue fever. Int J Pharma Sci Inv. 2014;3;1-5. [Crossref][PubMed][Google Scholar]

15. Ralapanawa U, Alawattegama AT, Gunrathne M, Tennakoon S, Kularatne SA, Jayalath $\mathrm{T}$. Value of peripheral blood count for dengue severity prediction. BMC Res Notes. 2018;11(1)400. doi: 10.1186/s13104-018-3505-4 [Crossref][PubMed] [Google Scholar]

16. Kao CL, King CC, Chao DY, Wu HL, Chang GJ. Laboratory diagnosis of dengue virus infection: current and future perspectives in clinical diagnosis and public health. J Microbiol Immunol Infect. 2005;38(1)5-16. [Crossref][PubMed][Google Scholar]

17. Ageep AK, Malik AA, Elkarsani MS. Clinical presentations and laboratory findings in suspected cases of dengue virus. Saudi Med J. 2006;27(11)1711-1713. [Crossref][PubMed][Google Scholar]

18. Advani S, Agarwal S, Verma J. Haemogram profile of dengue fever in adults during 19 September - 12 November 2008- A study of 40 cases from Delhi. Dengue Bulletin. 2011;3571-75. [Crossref][PubMed][Google Scholar]

19. Rusmawati I, Asma Hanim H, Naznin M, Salman MS, Norlelawati AT. A descriptive study of blood films of patients serologically positive for dengue in Hospital Tengku Ampuan Afzan, Kuantan. Int Med J Malaysia. 2010;9(2)35-37. [Crossref][PubMed] [Google Scholar] 
20. Dutta $P$, Khan SA, Borah J, Mahanta J. Demographic and clinical features of patients with dengue in Northeastern region of India- A retrospective cross-sectional study during 20092011. J Virol Microbiol. 2012;1-11. doi: 10.5171/2012.786298 [Crossref][PubMed][Google Scholar]

21. Arshad I, Malik FA, Hussain A, Shahida A. Dengue fever clinico-pathologic correlations and their association with poor outcome. Professional Med J. 2011;18(1)57-63. [Crossref][PubMed] [Google Scholar]

22. Jameel T, Mehmood K, Mujtaba G, Choudhry N, Afzal N, Paul RF. Changing haematological parameters in dengue viral infections. J Ayub Med Coll Abbottabad. 2012;24(1)3-6. [Crossref] [PubMed][Google Scholar]

23. Rashmi MV, Hamsaveena. Haematological and biochemical markers as predictors of dengue infection. Malaysian J Pathol. 2015;37(3)247-251. [Crossref][PubMed][Google Scholar]

24. Joshi AA, Gayathri BR, Muneer F. Dynamics of differential count in dengue. Int J Adv Med. 2018;5(1)145-150. Doi: $\quad$ 10.18203/23493933.ijam20180074 [Crossref][PubMed][Google Scholar]

25. Harnett WL. The Differential Blood Count in Dengue. Ind Med Gaz. 1913;48(2)45-49. [Crossref] [PubMed][Google Scholar]
26. Cabar FR, Fettback PB, Pereira PP, Zugaib M. Serum markers in the diagnosis of tubal pregnancy. Clinics (Sao Paulo). 2008;63(5)701-8. doi: 10.1590/s1807-59322008000500021 [Crossref] [PubMed][Google Scholar]

27. Khandal A, Raghuraman D. Rising Mean Platelet Volume (MPV) Heralding Platelets Recovery in Dengue?. Am J Clin Med Res. 2017;5(4)59-63. doi: 10. 12691/ajcmr-5-4-5 [Crossref][PubMed][Google Scholar]

28. Navya BN, Patil S, Kariappa TM. Role of Platelet Parameters in Dengue Positive Cases- An Observational Study. Int J Health Sci Res. 2016;6(6)7478. [Crossref][PubMed][Google Scholar]

29. Vagdatli E, Gounari E, Lazaridou E, et al. Platelet distribution width- a simple, practical and specific marker of activation of coagulation. Hippokratia. 2010; 14(1)28-32. [Crossref][PubMed][Google Scholar]

30. Bashir AB, Saeed OK, Mohammed BA, Ageep AK. Role of Platelet Indices in Patients with Dengue Infection in Red Sea State, Sudan. Int J Sci Res. 2015;4(1)1573-1576. [Crossref][PubMed][Google Scholar]

31. Gawlita M,Wasilewski J, Osadnik T, Regula R, Bujak K, Gonera M. Mean platelet volume and platelet large cell ratio as prognostic factors for coronary artery disease and myocardial infarction. Folia Cardiologica. 2015;10(6)418-422. doi: 10.5603/FC.2015.0079 [Crossref][PubMed][Google Scholar] 